\title{
Decreasing Medication Turnaround Time with Digital Scanning Technology in a Canadian Health Region
}

\author{
Heather Neville, Lisa Nodwell, and Sahar Alsharif
}

\begin{abstract}
Background: Reducing medication turnaround time can improve efficiency, patient safety, and quality of care in the hospital setting. Digital scanning technology (DST) can be used to electronically transmit scanned prescriber orders to a pharmacy computer queue for verification and processing, which may help to improve medication turnaround time.

Objectives: To evaluate medication turnaround time before and after implementation of DST for all medications and for antibiotics only.

Methods: Medication turnaround times were evaluated retrospectively for periods before (June 6-10, 2011) and after (September 26-30, 2011) implementation of DST at 2 hospital sites in 1 health region. Medication turnaround time was defined as the time from composition of a medication order by the prescriber to its verification by the pharmacy (phase 1) and the time from prescriber composition to administration to the patient by a nurse (total). Median turnaround times were analyzed with SPSS software using the Mann-Whitney $U$ test.

Results: In total, 304 and 244 medication orders were audited before and after DST implementation, respectively. Median phase 1 turnaround time for all medications declined significantly, from $2 \mathrm{~h} 23 \mathrm{~min}$ before DST implementation to $1 \mathrm{~h} 33 \mathrm{~min}$ after DST implementation $(p<0.001)$. Antibiotics were also processed significantly faster $(1 \mathrm{~h} 51 \mathrm{~min}$ versus $1 \mathrm{~h} 9 \mathrm{~min}, p=0.015)$. However, total turnaround time for all medications did not differ significantly ( 5 h 15 min versus 5 h 0 min, $p=0.42$ ).

Conclusions: Implementation of DST was associated with a 50-min decrease in medication turnaround time for the period from when an order was prescribed to the time it was processed by the pharmacy. Regular evaluation of medication turnaround times is recommended to compare with benchmarks, to ensure that hospital standards are being met, and to measure the effects of policy changes and implementation of new technology on medication-use processes.
\end{abstract}

Keywords: digital scanning technology, medication turnaround time, order processing

\section{RÉSUMÉ}

Contexte : La réduction des délais d'exécution d'ordonnances de médicaments peut améliorer l'efficacité, la sécurité des patients et la qualité des soins dans les hôpitaux. Une technologie de numérisation peut être utilisée pour envoyer, par des moyens électroniques, les ordonnances numérisées des prescripteurs aux files d'attente des ordinateurs de pharmacies afin qu'elles soient vérifiées et traitées, ce qui pourrait aider à améliorer leurs délais d'exécution.

Objectifs : Déterminer les délais d'exécution d'ordonnances avant et après la mise en place d'une technologie de numérisation pour l'ensemble des médicaments et pour les antibiotiques seulement.

Méthodes : Les délais d'exécution d'ordonnances ont fait l'objet d'une évaluation rétrospective pour les périodes précédant (du 6 au 10 juin 2011) et suivant (du 26 au 30 septembre 2011) la mise en place d'une technologie de numérisation dans deux hôpitaux d'une régie régionale de la santé. La phase 1 du délai d'exécution d'une ordonnance représentait la période allant de sa rédaction par le prescripteur à sa vérification en pharmacie et le délai total d'exécution d'une ordonnance était défini comme la période allant de sa rédaction par le prescripteur à l'administration du médicament au patient par le personnel infirmier. Les délais médians d'exécution ont été analysés par le logiciel SPSS à l'aide du test $U$ de Mann-Whitney.

Résultats : En tout, 304 et 244 ordonnances ont été évaluées respectivement avant et après la mise en place d'une technologie de numérisation. Le délai médian d'exécution relatif à la phase 1 s'est considérablement raccourci pour l'ensemble des médicaments, de 2 heures 23 minutes avant la mise en place de la technologie de numérisation à 1 heure 33 minutes après sa mise en place $(p<0.001)$. Les antibiotiques ont eux aussi été traités beaucoup plus rapidement (1 heure 51 minutes contre 1 heure 9 minutes, $p=0.015$ ). Par contre, le délai total d'exécution pour l'ensemble des médicaments ne variait que très peu ( 5 heures 15 minutes contre 5 heures 0 minute, $p=0.42$ ).

Conclusions : La mise en place d'une technologie de numérisation a été associée à une réduction de 50 minutes de la portion du délai d'exécution d'ordonnances comprise entre la rédaction de l'ordonnance et le moment où elle était traitée à la pharmacie. Il est recommandé de faire l'évaluation régulière des délais d'exécution d'ordonnances afin de comparer à des étalons, de s'assurer que les standards de l'hôpital sont respectés et de mesurer l'influence des changements de politiques et de la mise en place de nouvelles technologies sur les processus de distribution des médicaments.

Mots clés : technologie de numérisation, délai d'exécution d'ordonnance, traitement des ordonnances

[Traduction par l'éditeur] 


\section{INTRODUCTION}

$\mathrm{H}^{2}$ ealth care technologies such as the electronic health record, computerized provider order entry, and automated dispensing systems can reduce adverse drug events and improve the efficiency of the medication-use process. ${ }^{1-4}$ One measure of the efficiency of medication use is medication turnaround time, which indicates whether a drug is available on the nursing unit for administration to the patient in a timely manner. Medication turnaround time is the total time from composition of an order by the prescriber, through verification and processing in the pharmacy, to administration of the medication to the patient. ${ }^{5,6}$ Medication turnaround time has also been defined as the time it takes for the pharmacy to process a medication order. ${ }^{7,8}$ Evidence suggests that decreasing medication turnaround time can improve patient care, particularly for medications that have a critical impact on patient outcomes. ${ }^{6}$ For example, timely administration of antibiotics prescribed for community-acquired pneumonia, sepsis, and meningitis has decreased mortality rates and length of stay. ${ }^{9-11}$

The use of paper-based charts and manually written medication orders is still common practice in many Canadian hospitals. ${ }^{12}$ Carbon copies of medication orders are removed from the patient chart and delivered by hand or sent by fax or through a pneumatic tube system to the pharmacy for processing. Disadvantages of a paper-based system include delays in receipt of medication orders in the pharmacy, loss of orders, equipment failure, and illegibility. ${ }^{13}$ Pharmacy staff are diverted from focused tasks (such as prescription order entry and order checking) to resolve issues related to delivery of medication orders, which results in delays in processing medication orders and a potentially increased risk of errors. ${ }^{8,14}$ Tracking medication orders and answering questions about the status of medication order processing are time-consuming tasks and represent a source of frustration for pharmacy and nursing staff. ${ }^{8,15}$

To address these issues, some pharmacies have implemented digital scanning technology (DST), with the goals of improving medication turnaround time and enhancing order-processing efficiency, thereby improving patient care. ${ }^{8,13-15}$ Staff working in a patient care area use DST to fax medication orders written on paper to a computerized queue for immediate viewing and processing by pharmacy staff. In addition to rapid processing and digitization, other benefits of DST include support of centralized order entry for multiple hospital sites ${ }^{14}$ and improvements in communication, retrieval of patient information, and storage of medication orders. ${ }^{13}$ However, the effect of DST on total medication turnaround time has not been well described in the literature. Most reports with detailed information on medication turnaround time have compared a paper-based system or DST with computerized provider order entry and other electronic systems. ${ }^{2,5,6,10,16-18}$

The primary objective of this investigation was to evaluate total medication turnaround time for all medication orders for defined periods before and after implementation of DST. Total medication turnaround time was measured from composition of the order to administration of the medication to the patient. Secondary objectives were to evaluate the effect of DST on total medication turnaround time for the first dose of antibiotics only and on the first phase of medication turnaround time, defined as the time from composition of the order by the prescriber to pharmacy processing of the order (i.e., reviewing the order, entering the order on the patient's profile, and generating a label to dispense the medication).

\section{METHODS}

\section{Setting}

This retrospective evaluation of medication turnaround time was conducted at the Halifax Infirmary and the Victoria General, 2 tertiary care centres in the Capital District Health Authority (Capital Health) in Nova Scotia, Canada. Capital Health provides health programs and services to a local population of 400000 , in addition to providing critical, trauma, and specialized services for Atlantic Canada. ${ }^{19}$ Data for the Dartmouth General Hospital, a community hospital in Capital Health, were collected and underwent initial evaluation. However, this hospital experienced changes to the pharmacy's medication distribution system at the same time as implementation of DST, so the data were excluded from the final analysis. The Halifax Infirmary had 400 beds and 132586 patient-days in fiscal year 2010/2011. The Victoria General had 210 beds and 69898 patient-days in the same fiscal year. Each hospital had a central pharmacy where inpatient medication orders were processed in a 24-h unit-dose and centralized IV admixture distribution system.

Before implementation of DST, medication orders were either faxed by nursing staff or delivered by porter services to the pharmacy. The Halifax Infirmary also received orders via a pneumatic tube system. A pharmacist clinically evaluated each order and, if appropriate, entered it on the patient's computerized profile in BDM Pharmacy (version 9.0, BDM IT Solutions, Saskatoon, Saskatchewan). Any order that required clarification was set aside for follow-up by a clinical pharmacist assigned to the service where the order was written or by the dispensary pharmacist, if a clinical pharmacist was not available. Pharmacy technicians dispensed first doses as interim doses; subsequent doses were dispensed in 24-h unit-dose trays for both of the hospitals. Porters picked up the dispensed medications at regular times through the day and delivered them to the patient care areas. The Halifax Infirmary also had the option of sending dispensed medications through the pneumatic tube system. Nurses received the medications and administered them to patients at standard times according to hospital policy, unless the physician had specified a different time or it was an urgent ("stat") dose. 
A DST system from BDM Pharmacy, called Orders Connect, was implemented on June 13, 2011, at the Victoria General and on June 20, 2011, at the Halifax Infirmary. Fax machines in every patient care area were reprogrammed with 2 fax numbers: one for regular orders and the other for "stat" orders. All orders were scanned digitally and sent to the pharmacy fax queue. Dispensary work stations were equipped with dual monitors so that a pharmacist could review the fax image of an order on one screen and enter the prescription into the patient profile on the second screen. Both porter delivery and the tube system were eliminated as methods of receiving orders. Throughout the implementation period, procedures related to pharmacy processing and dispensing, as well as medication administration by nursing staff, remained the same. For this quality assurance study, ethics approval was not required by the Capital Health Research Ethics Board.

\section{Sample Size}

Sample size calculations were performed using G*Power software (version 3.1.9.2, Universität Kiel, Kiel, Germany) based on phase 1 turnaround time. Current phase 1 turnaround time was estimated to be $4 \mathrm{~h}$, and DST was projected to reduce medication turnaround time by $25 \%$ (to $3 \mathrm{~h}$ ), with a standard deviation of 225 min. ${ }^{5}$ The required sample size was calculated as 297 orders in each group, to give a 2 -tailed $\alpha$ of $<0.05$ and $90 \%$ power.

\section{Data Collection}

Data collection periods were June 6-10, 2011 (before DST implementation), and September 26-30, 2011 (after DST implementation). The post-implementation data collection period was initiated 3 months following implementation to ensure that the technology was operating effectively and that users were proficient. For each eligible medication order, data were collected for patient information (name, medical record number, visit number, sex, birth date, admission date, admitting service, admitting location, hospital site), medication information (drug name, dose, directions, route of administration), and medication turnaround time (prescriber composition time and date, pharmacy order verification time and date, patient administration time and date). The time from pharmacy processing to availability of the medication in the patient care area was not available and could not be measured.

\section{Inclusion and Exclusion Criteria}

Orders for each study period were exported from the pharmacy information system and screened against the exclusion criteria. Eligible inpatient orders were those processed between the hours of 0900 and 2300 Monday to Friday for the defined periods (before and after DST implementation) at each of the 2 hospitals. Medication orders had to be signed by an authorized prescriber, with date and time recorded. Verbal orders (in person or by telephone) from a prescriber to a nurse were also accepted if the date and time were recorded. For total turnaround time, only orders for medications that were administered to patients on the same day were included in the analysis. For phase 1 turnaround times (order composition to verification), medications administered the next day were included. Orders for new medications and orders involving an increase in dose or frequency or a change in route of administration were included. For order sheets that contained more than one prescription, only one medication was audited from each order sheet, to ensure that each medication order could be considered independently. Including a batch of orders with very similar turnaround times could artificially increase or decrease the average medication turnaround time. In these cases, the first antibiotic listed on the order sheet was chosen for analysis, to maximize the number of antibiotics sampled; if the order sheet listed no antibiotics, the first medication on the order sheet was audited.

Orders written on weekends were excluded, because staffing levels were lower on weekends than on weekdays. Similarly, the early hours of each weekday morning were excluded, since staff spent that time processing orders written while the pharmacy was closed overnight. Also excluded were orders for medications stocked in patient care areas, medications not regularly scheduled (e.g., to be taken when needed), self-administered medications, and patients' own medications. Orders that had to be clarified by a pharmacist were ineligible, as were orders for total parenteral nutrition or chemotherapy because of the specialized processing required on the part of pharmacy staff.

\section{Statistical Analysis}

Medication turnaround time was calculated for phase 1 (from prescriber composition to verification by pharmacy) and total time (from prescriber composition to administration to the patient). Medication orders were analyzed in 3 groups: all medications, antibiotics only, and all non-antibiotic agents.

Medication turnaround times were descriptively analyzed as medians (with 25th and 75th percentiles) for both definitions of turnaround time and all medication groups. Medians were used to reduce the effect of extreme values on the measure of central tendency and to better describe skewed data. Median turnaround time was compared before and after DST implementation for phase 1 and total turnaround times using the Mann-Whitney $U$ test for nonparametric data. All medications and first doses of antibiotics were analyzed separately to determine if there was a statistically significant difference related to type of medication. All data were analyzed with SPSS software (version 15.0, SPSS Inc, Chicago, Illinois). 


\section{RESULTS}

The number of orders contributed from each site was related to the hospital's patient-days (Table 1). The medication order report of the pharmacy information system listed 40654 records for June 6-10, 2011, and 39742 records for September 26-30, 2011, for the 2 hospitals combined. After screening and application of inclusion and exclusion criteria, a total of 304 orders for the period before DST implementation and 244 orders for the period after DST implementation were included in the analysis. The initial evaluation included orders from the third community hospital, to reach the desired sample size, but these were subsequently excluded from the study, as noted above. The most common reason for excluding an order (after initial screening) was absence of prescriber composition time in the patient's record, which occurred for 1264 (65\%) of 1944 orders excluded for the period before DST implementation and for 880 (75\%) of 1174 orders excluded for the period after DST implementation.

Median medication turnaround times (phase 1 and total) are displayed in Tables 2 and 3, respectively. Phase 1 turnaround time declined significantly for all medications (decrease of $50 \mathrm{~min}, p<0.001$ ) and for antibiotics alone (decrease of $42 \mathrm{~min}$, $p=0.015)$. There were no significant differences in total turnaround time. For all medications, the median total turnaround time was $5 \mathrm{~h}, 15 \mathrm{~min}$ before DST implementation and $5 \mathrm{~h}$ after DST implementation.

\section{DISCUSSION}

The primary objective of this study was to evaluate medication turnaround time for all medication orders in defined periods before and after implementation of DST in 2 hospitals within a single health region. For all medication orders, medication turnaround time during the first phase of order processing (i.e., the time from prescriber order composition to pharmacy order verification) declined by $50 \mathrm{~min}$. Although many factors affect turnaround time, DST was associated with an increase in the efficiency and consistency of order delivery to the pharmacy. For example, DST eliminated dependence on a porter delivery schedule and thereby provided a highly reliable method of delivering orders to the pharmacy, which may have reduced the frequency of missing orders and resulting phone calls. As well, this technology generated a more legible prescription for the pharmacist to review, potentially reducing phone calls to nursing and medical staff for clarifications.

Few studies have evaluated turnaround time for a digital scanning form of technology, and within these studies, the definition of medication turnaround time was limited to pharmacy processing time. ${ }^{8,14,15}$ Carswell and others ${ }^{15}$ documented a reduction from $43 \mathrm{~min}$ (with a paper-based system) to $9.4 \mathrm{~min}$ (with a digital scanning system) for the time between the order reaching the pharmacy and completion of processing in the pharmacy. Cronk, ${ }^{14}$ using the same definition of turnaround time as Carswell and others, ${ }^{15}$ observed a processing time of 13-14 minutes, with the drug being made available in automated dispensing cabinets within 1-9 min after processing. Sikri and others ${ }^{8}$ compared a system in which paper orders were faxed to traditional fax machines with a system in which paper orders were scanned to a digital fax queue. The reported turnaround time decreased from $41 \mathrm{~min}$ to $27 \mathrm{~min} .{ }^{8}$ The times recorded in the current study were considerably longer, which may have been related to volume of orders and staffing levels. The current evaluation is unique because it measured the first phase of medication turnaround, as well as total turnaround time (from prescriber composition to patient administration).

The secondary objective of this study was to determine the impact of DST implementation on turnaround time for antibiotics, which are considered more critical than other medications. Following DST implementation, antibiotics were processed $42 \mathrm{~min}$ faster by the pharmacy (i.e., phase 1 turnaround time). This result may be explained by the use of a "stat" fax queue, whereby nurses could assign high-priority status to orders needed urgently, with these faxes always being processed first by pharmacy staff. One disadvantage of the fax queue system is that pharmacy staff cannot prescreen orders in the regular-priority queue. It was common practice before DST implementation for pharmacists to quickly review the stack of paper orders to identify urgent medications and process them first. After DST implementation, however, pharmacy staff were reliant on nursing staff to use the "stat" and regular fax lines appropriately. No difference in total turnaround time was noted for first doses of antibiotics, but this result may be related to the small sample size and/or the definition of eligible orders. The analysis included all first doses

Table 1. Number of Orders Available, Screened, and Included (by Hospital)

\begin{tabular}{|c|c|c|c|c|c|c|c|}
\hline \multirow{3}{*}{ Site* } & \multirow{3}{*}{ Target } & \multicolumn{6}{|c|}{ Study Period; No. of Orders } \\
\hline & & \multicolumn{3}{|c|}{ Before DST } & \multicolumn{3}{|c|}{ After DST } \\
\hline & & Available & Screened & Included & Available & Screened & Included \\
\hline Halifax Infirmary & 156 & 3248 & 1563 & 215 & 2553 & 866 & 158 \\
\hline Victoria General Hospital & 84 & 1710 & 685 & 89 & 1395 & 552 & 86 \\
\hline Total & 240 & 4958 & 2248 & 304 & 3948 & 1418 & 244 \\
\hline
\end{tabular}

DST = digital scanning technology.

*Both sites were within the Capital District Health Authority, Halifax, Nova Scotia. 
This single copy is for your personal, non-commercial use only.

For permission to reprint multiple copies or to order presentation-ready copies for distribution, contact CJHP at cjhpedit@cshp.ca

Table 2. Medication Turnaround Times during Phase 1*

\begin{tabular}{|c|c|c|c|c|c|}
\hline \multirow[t]{2}{*}{ Medication Group } & \multicolumn{2}{|c|}{ Before DST } & \multicolumn{2}{|c|}{ After DST } & \multirow[b]{2}{*}{$p$ Value } \\
\hline & $\begin{array}{l}\text { No. of } \\
\text { Orders }\end{array}$ & $\begin{array}{c}\text { Median } \\
\text { Turnaround Timet }\end{array}$ & $\begin{array}{l}\text { No. of } \\
\text { Orders }\end{array}$ & $\begin{array}{c}\text { Median } \\
\text { Turnaround Timet }\end{array}$ & \\
\hline All medications & 304 & $\begin{array}{c}2: 23 \\
(1: 06,4: 08)\end{array}$ & 244 & $\begin{array}{c}1: 33 \\
(0: 33,3: 21)\end{array}$ & $<0.001$ \\
\hline Antibiotics & 54 & $\begin{array}{c}1: 51 \\
(0: 58,3: 17)\end{array}$ & 47 & $\begin{array}{c}1: 09 \\
(0: 33,2: 07)\end{array}$ & 0.015 \\
\hline Non-antibiotics & 250 & $\begin{array}{c}2: 31 \\
(1: 08,4: 21)\end{array}$ & 197 & $\begin{array}{c}1: 35 \\
(0: 33,3: 39)\end{array}$ & 0.006 \\
\hline
\end{tabular}

DST = digital scanning technology.

* Phase I = time from order composition to pharmacy verification.

†Median time (with 25th and 75th percentiles in parentheses) expressed as hours:minutes.

Table 3. Total* Medication Turnaround Times

\begin{tabular}{|c|c|c|c|c|c|}
\hline \multirow[t]{2}{*}{ Medication Group } & \multicolumn{2}{|c|}{ Before DST } & \multicolumn{2}{|c|}{ After DST } & \multirow[b]{2}{*}{$p$ Value } \\
\hline & $\begin{array}{l}\text { No. of } \\
\text { Orders }\end{array}$ & $\begin{array}{c}\text { Median } \\
\text { Turnaround Timet }\end{array}$ & $\begin{array}{l}\text { No. of } \\
\text { Orders }\end{array}$ & $\begin{array}{c}\text { Median } \\
\text { Turnaround Timet }\end{array}$ & \\
\hline All medications & 201 & $\begin{array}{c}5: 15 \\
(3: 27,8: 00)\end{array}$ & 138 & $\begin{array}{c}5: 00 \\
(3: 00,8: 00)\end{array}$ & 0.42 \\
\hline Antibiotics & 42 & $\begin{array}{c}4: 45 \\
(2: 44,7: 32)\end{array}$ & 30 & $\begin{array}{c}4: 42 \\
(3: 08,6: 33)\end{array}$ & 0.88 \\
\hline Non-antibiotics & 159 & $\begin{array}{c}5: 30 \\
(3: 40,8: 05)\end{array}$ & 108 & $\begin{array}{c}5: 05 \\
(2: 55,8: 38)\end{array}$ & 0.35 \\
\hline
\end{tabular}

DST = digital scanning technology.

*Total time $=$ time from order composition to administration of the medication to the patient.

tMedian time (with 25th and 75th percentiles in parentheses) expressed as hours:minutes.

of antibiotics intended for both oral and IV administration. Given this definition, data related to step-down from IV to oral antibiotics would have been included, but medication orders for first doses of oral antibiotics would not have the same urgency as first doses of IV antibiotics. An institutional policy to standardize turnaround time for first doses of IV antibiotics did not exist at the time of the study, and practice was dependent on the judgment of individual health care providers.

This study had some limitations. The number of orders audited met the planned sample size for the period before DST implementation, but not the period after DST implementation, because orders from one of the hospital sites were excluded after the study was complete. The sample size calculations were based on assumptions derived from the literature, which varied greatly from practices in the study region. Nevertheless, a larger sample size would provide more confidence that the point estimates reflected true medication turnaround times. A second limitation was the lack of documentation (at the time the study was conducted) of the times when medication orders were received in the pharmacy and when prepared medications left the pharmacy and were delivered to the patient care area. In particular, paper orders were not time-stamped upon receipt in the pharmacy, and medications left the pharmacy every 1 to $2 \mathrm{~h}$, according to the porter delivery schedule. The DST system is still in place in the health region, and a software upgrade has since been implemented; as a result, the time when each order is received in the fax queue is now available. However, delays in pharmacy dispensing and delivery during the 2 study periods may have resulted in longer total medication turnaround times. A third limitation was the frequent absence of a prescriber composition time for medication orders. As a result, a large proportion of medication orders had to be excluded (65\%-75\% of those screened), including physicians' preprinted order sets and admission medication reconciliation forms, because these forms lacked a field where the prescriber could record the time of composition. Use of computerized provider order entry systems would significantly improve documentation of medication turnaround time by automating the process and allowing for generation of computerized turnaround time reports. Finally, data for turnaround time relied on the prescribing and administration times documented by hand in patients' charts, which could not be verified for accuracy.

Although this evaluation focused solely on medication turnaround time, there are many potential benefits that may influence the decision to implement DST. These factors include cost savings and environmental benefits from the elimination of non-carbon copy paper orders, improved legibility of medication orders, and electronic filing of medication orders, which allows for ease of retrieval and prevents loss of orders. DST also allows remote order entry processing, which can lead to a flexible staffing model within multisite facilities, to assist in dealing with variable order volumes. In the health region where this study was 
conducted, remote order entry facilitated the implementation of decentralized medication order processing by clinical pharmacists located in the patient care areas. Computerized provider order entry technology offers similar benefits; however, in contrast to DST, it is costly and time-consuming to implement. ${ }^{20,21}$

\section{CONCLUSIONS}

Implementation of DST in 2 tertiary care hospitals was associated with a 50-min decrease in phase 1 medication turnaround time and an improvement of $42 \mathrm{~min}$ in phase 1 turnaround time for first doses of antibiotics. These results suggest the need for interprofessional education to review policies on medication turnaround time and to reinforce the rationale for minimum standard turnaround times for critical medications, including antibiotics. Regular evaluation of medication turnaround times is recommended to compare with benchmarks, to ensure hospital standards are being met, and to measure the effects of policy changes and implementation of new technology on medication-use processes.

\section{References}

1. Anderson JG, Jay SJ, Anderson M, Hunt TJ. Evaluating the impact of information technology on medication errors: a simulation. J Am Med Inform Assoc. 2003;10(3):292-3.

2. Cunningham TR, Geller ES, Clarke SW. Impact of electronic prescribing in a hospital setting: a process-focused evaluation. Int J Med Inform. 2008; 77(8):546-54.

3. Kaushal R, Shojania KG, Bates DW. Effects of computerized physician order entry and clinical decision support systems on medication safety: a systematic review. Arch Intern Med. 2003;163(12):1409-16.

4. Cheng CM. Hospital systems for the detection and prevention of adverse drug events. Clin Pharmacol Ther. 2011;89(6):779-81.

5. Wietholter J, Sitterson S, Allison S. Effects of computerized prescriber order entry on pharmacy order-processing time. Am J Health Syst Pharm. 2009;66(15):1394-8.

6. Mekhjian HS, Kumar RR, Kuehn L, Bentley TD, Teater P, Thomas A, et al. Immediate benefits realized following implementation of physician order entry at an academic medical center. J Am Med Inform Assoc. 2002;9(5):529-39.

7. Naylor H, Woloschuk DM, Fitch P, Miller S. Retrospective audit of medication order turnaround time after implementation of standardized definitions. Can J Hosp Pharm. 2011;64(5):346-53.

8. Sikri S, Sansgiry SS, Sanborn MD, Flinn M. Effect of a remote order scanning system on processing medication orders. Am J Health Syst Pharm. 2006;63(15):1438-41.

9. Houck PM, Bratzler DW, Nsa W, Ma A, Bartlett JG. Timing of antibiotic administration and outcomes for medicare patients hospitalized with community-acquired pneumonia. Arch Intern Med. 2004;164(6):637-44.

10. Cartmill RS, Walker JM, Blosky MA, Brown RL, Djurkovic S, Dunham $\mathrm{DB}$, et al. Impact of electronic order management on the timeliness of antibiotic administration in critical care patients. Int J Med Inform. 2012; 81(11):782-91.

11. Battleman DS, Callahan M, Thaler HT. Rapid antibiotic delivery and appropriate antibiotic selection reduce length of hospital stay of patients with community-acquired pneumonia: link between quality of care and resource utilization. Arch Intern Med. 2002;162(6):682-8.
12. Macgregor P, Hall K. Technology. In: Babich M, Bornstein C, Bussières JF, Doucette D, Hall K, Lefebvre P, et al., editors. Hospital pharmacy in Canada 2011/2012 report. Eli Lilly; 2012 [cited 2014 Jan 16]. Available from: www.lillyhospitalsurvey.ca/hpc2/content/2012_report/chapter_e\%20.pdf

13. Simonian AI. Medication order communication using fax and documentimaging technologies. Am J Health Syst Pharm. 2008;65(6):570-3.

14. Cronk JD. Digital scanning and consolidated entry of medication orders in a multihospital health system. Am J Health Syst Pharm. 2002;59(8):731-3.

15. Carswell J, DiPiro C, Gomez T, Phillips M, Herrington B. Evaluation of turnaround time for medication order processing with use of a novel scanning system. Hosp Pharm. 2006;41(3):249-53.

16. Panosh N, Rew R, Sharpe M. Effect of closed-loop order processing on the time to initial antimicrobial therapy. Am J Health Syst Pharm. 2012;69(16): 1423-6.

17. Wess ML, Embi PJ, Besier JL, Lowry CH, Anderson PF, Besier CJ, et al. Effect of a computerized provider order entry (CPOE) system on medication orders at a community hospital and university hospital. AMIA Annu Symp Proc. 2007:796-800.

18. Jensen JR. The effects of computerized provider order entry on medication turn-around time: a time-to-first dose study at the Providence Portland Medical Center. AMIA Annu Symp Proc. 2006:384-8.

19. About us [website]. Halifax (NS): Capital Health; [cited 2014 Nov 21]. Available from: www.cdha.nshealth.ca/about-us

20. Campbell EM, Sittig DF, Ash JS, Guappone KP, Dykstra RH. Types of unintended consequences related to computerized provider order entry. $J$ Am Med Inform Assoc. 2006;13(5):547-56.

21. Kaushal R, Jha AK, Franz C, Glaser J, Shetty KD, Jaggi T, et al. Return on investment for a computerized physician order entry system. J Am Med Inform Assoc. 2006;13(3):261-6.

Heather Neville, BScPharm, MSc, is a Drug Utilization Pharmacist with the Capital District Health Authority, Halifax, Nova Scotia.

Lisa Nodwell, BSCPharm, ACPR, is a Clinical Pharmacist with the Capital District Health Authority, Halifax, Nova Scotia.

Sahar Alsharif, PharmD, MHI, is a Pharmacist with the King Faisal Specialist Hospital and Research Center, Jeddah, Saudi Arabia.

Competing interests: None declared.

Address correspondence to:

Heather Neville

Capital District Health Authority

Room 2043, Victoria General

1276 South Park Street

Halifax NS B3H 2 Y9

e-mail: Heather.neville@cdha.nshealth.ca

\section{Acknowledgements}

The authors gratefully acknowledge Christopher Daley for his presubmission review of the manuscript and helpful comments. 